\title{
Haplofungins, new inositol phosphorylceramide synthase inhibitors, from Lauriomyces bellulus SANK 26899 II. Structure elucidation
}

\author{
Takashi Ohnuki $^{1}$, Tatsuya Yano ${ }^{2}$ and Toshio Takatsu ${ }^{1}$ \\ Eight new inositol phosphorylceramide synthase inhibitors: haplofungin A, B, C, D, E, F, G and H, were discovered in a culture \\ broth of the fungus Lauriomyces bellulus SANK 26899. The planar structures for these haplofungins were elucidated by various \\ spectroscopic analyses and a GC/MS analysis of their degradation products. All eight compounds were found to comprise an \\ arabinonic acid moiety linked through an ester bond to a modified long alkyl chain.
}

The Journal of Antibiotics (2009) 62, 551-557; doi:10.1038/ja.2009.73; published online 31 July 2009

Keywords: antifungal; haplofungin; inhibitor; inositol phosphorylceramide synthase; physicochemical properties; sphingolipid; structure

\section{INTRODUCTION}

In our screening program for new inositol phosphorylceramide (IPC) synthase inhibitors, we discovered eight new compounds named haplofungin A (1), B (2), C (3), D (4), E (5), F (6), G (7) and H (8) from a culture broth of Lauriomyces bellulus SANK 26899 (Figure 1). In the preceding paper, ${ }^{1}$ we described the taxonomy of the producing strain and the production, isolation and biological activities of these haplofungins. Here, we report the physicochemical properties and structure elucidation of these haplofungins.

\section{RESULTS}

Physicochemical properties

The physicochemical properties of 1-8 are summarized in Table 1. These compounds were soluble in methanol, ethyl acetate and dimethylsulfoxide, but were insoluble in water and $n$-hexane. The IR spectra of these compounds showed characteristic absorption bands for hydroxyl $\left(3400 \mathrm{~cm}^{-1}\right)$, carbonyl and carboxyl groups (1740$\left.1661 \mathrm{~cm}^{-1}\right)$. The similarity of the UV spectra $\left(\lambda_{\max } 236-238 \mathrm{~nm}\right)$ of these compounds indicated that they have the same $\alpha, \beta$-unsaturated carbonyl system. ${ }^{1} \mathrm{H}$ and ${ }^{13} \mathrm{C} \mathrm{NMR}$ data of haplofungins are summarized in Tables 2 and 3, respectively.

\section{Structure elucidation of haplofungins}

Structure of 1 . The structure of $\mathbf{1}$ was established on the basis of the NMR and MS data. The molecular formula of $\mathbf{1}$ was determined to be $\mathrm{C}_{33} \mathrm{H}_{60} \mathrm{O}_{9}$ based on high-resolution time-of-flight mass spectrometry (HRTOF-MS), which gave an $(\mathrm{M}+\mathrm{Na})^{+}$ion at $\mathrm{m} / z 623.4122$ (calculated for $\left.\mathrm{C}_{33} \mathrm{H}_{60} \mathrm{O}_{9} \mathrm{Na}, 623.4135\right)$. The ${ }^{13} \mathrm{C}$ NMR spectra indicated that
1 contains five methyls, 15 methylenes, one oxygenated methylene, three methines, four oxygenated methines, one $s p^{2}$ methine, one $s p^{2}$ quaternary carbon, one carbonyl carbon, one ester carbonyl carbon and one carboxyl carbon. To fulfill the molecular formula of 1 , the presence of four hydroxyl groups was suggested. The presence of a long alkyl chain was readily inferred from a broad equivalent signal resonating from $\delta 1.26$ to $\delta 1.32$, which was observed in the ${ }^{1} \mathrm{H}$ NMR spectrum. The connectivity of protons and carbons was established by the heteronuclear single quantum coherence (HSQC) spectrum. Double quantum filtered correlation spectroscopy (DQF COSY) and heteronuclear single quantum coherence homonuclear HartmannHahn spectroscopy (HSQC-HOHAHA) experiments showed the three proton spin systems drawn in bold lines (Figure 2). The first proton spin system was found to be a long alkyl chain moiety from the H-5 olefinic methine through the $\mathrm{H}$-13-oxygenated methine to the terminal methyl at $\mathrm{H}-24$. Two blanched methyl groups (C-27, C-28) connected to the C-6 and C- 8 methine carbons at $\delta 33.0$ and $\delta 32.1$ were also included in this system. The second proton spin system consisted of an $\mathrm{H}-2$ methine adjacent to an $\mathrm{H}-25$ methyl. The connectivities of three oxygenated methines ( $\mathrm{H}-2^{\prime}, \mathrm{H}-3^{\prime}$ and $\left.\mathrm{H}-4^{\prime}\right)$ and one oxygenated methylene $\left(\mathrm{C}-5^{\prime}\right)$ were established as the third spin system.

A heteronuclear multiple bond correlation (HMBC) experiment was used to confirm the assignments of above proton spin systems and establish the connectivity between the partial structures constructed above (Figure 2). The H-5 allylic methine proton at $\delta 6.64$, in the first spin system, was assigned at the $\beta$-position of $\alpha, \beta$-unsaturated carbonyl system by the observation of ${ }^{1} \mathrm{H}-{ }^{13} \mathrm{C}$ long-range correlations

${ }^{1}$ Exploratory Research Laboratories I, Daiichi Sankyo Co. Ltd, Hiromachi, Shinagawa-ku, Tokyo, Japan and ${ }^{2}$ Biological Research Laboratories II, Daiichi Sankyo Co. Ltd, Hiromachi, Shinagawa-ku, Tokyo, Japan

Correspondence: T Ohnuki, Exploratory Research Laboratories I, Daiichi Sankyo Co. Ltd, 1-2-58 Hiromachi, Shinagawa-ku, Tokyo 140-8710, Japan.

E-mail: ohnuki.takashi.eh@daiichisankyo.co.jp

Received 25 April 2009; revised 1 July 2009; accepted 7 July 2009; published online 31 July 2009 
from the H-5 olefinic proton to C-3 keto carbonyl and C-4 quaternary $s p^{2}$ carbon. The correlations with the $\mathrm{H}-26$ methyl group at $\delta 1.80$ to C-3, C-4 and C-5 confirmed the assignment of the methyl to be directly attached at C-4. The correlations with the H-25 methyl group

$$
\text { 24. }
$$

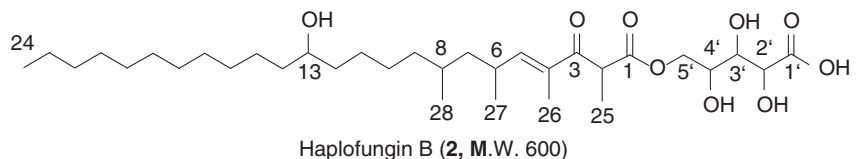

Figure 1 Structures of haplofungins. to C-2, C-1 ester carbonyl carbon and C-3 keto carbonyl carbon and from the $\mathrm{H}-2$ methine proton at $\delta 4.47$ to $\mathrm{C}-1, \mathrm{C}-3$ and $\mathrm{C}-4$ confirmed a 1,3-dicarbonyl-2-methyl system. The configuration of the $\Delta^{4}$ double bond was determined to be $E$ by NOEs observed between the H-26 methyl protons and the other two methyl protons at $\mathrm{H}-25$ and $\mathrm{H}-27$. The presence of an aldonate moiety in $\mathbf{1}$ was shown by the observation of the ${ }^{1} \mathrm{H}-{ }^{13} \mathrm{C}$ long-range coupling from oxygenated $\mathrm{H}-2^{\prime}$ methine proton at $\delta 4.05$ to $\mathrm{C}-1^{\prime}$ carboxyl carbon in the third spin system. As the long-range correlation with the $\mathrm{H}-4^{\prime}$-oxygenated methine proton at $\delta 4.97$ to C-1 ester carbonyl carbon was observed in the HMBC experiment, it was shown that the aldonate moiety was connected to the 1,3-dicarbonyl system through an ester bond between C-1 and C-4'.

To identify the aldonate, 1 was treated with $5 \% \mathrm{HCl} / \mathrm{MeOH}$ and then with N,O-bis-(trimethylsilyl)trifluoroacetamide (BSTFA). The reaction mixture was applied to GC/MS directly. The TMS derivative of the aldonate moiety was detected as a peak with a retention time of

\begin{tabular}{|c|c|c|c|c|}
\hline & 1 & 2 & 3 & 4 \\
\hline Appearance & White powder & White powder & White powder & White powder \\
\hline Molecular weight & 600 & 600 & 614 & 572 \\
\hline Molecular formula & $\mathrm{C}_{33} \mathrm{H}_{60} \mathrm{O}_{9}$ & $\mathrm{C}_{33} \mathrm{H}_{60} \mathrm{O}_{9}$ & $\mathrm{C}_{34} \mathrm{H}_{62} \mathrm{O}_{9}$ & $\mathrm{C}_{31} \mathrm{H}_{56} \mathrm{O}_{9}$ \\
\hline \multicolumn{5}{|l|}{ HR-MS $(m / z)$} \\
\hline Calculated: & 623.4135 & 623.4135 & 637.4291 & 595.3822 \\
\hline Found: & $623.4122(\mathrm{M}+\mathrm{Na})^{+\mathrm{a}}$ & $623.4134(\mathrm{M}+\mathrm{Na})^{+\mathrm{a}}$ & $637.4292(\mathrm{M}+\mathrm{Na})+{ }^{\mathrm{a}}$ & $595.3830(\mathrm{M}+\mathrm{Na})^{+}$b \\
\hline UV $\lambda_{\max }$ (methanol) $\mathrm{nm}(\varepsilon)$ & $238(5,970)$ & $236(8,588)$ & $236(7,970)$ & $236(10,800)$ \\
\hline \multirow[t]{4}{*}{$\mathrm{IR} v_{\max }(\mathrm{KBr}) \mathrm{cm}^{-1}$} & $3407,3137,2928,2856$ & $3353,2955,2919,2850$ & $428,2953,2925,2854$ & $3408,2926,2855$ \\
\hline & $1737,1679,1449,1381$ & $1785,1737,1666,1465$ & $2729,1744,1663,1456$ & $1740,1663,1457$ \\
\hline & $1316,1213,1146,1037$ & $1456,1377,1317,1283$ & $1376,1251,1216,1130$ & $1377,1312,1249$ \\
\hline & $845,803,726$ & $1251,1201,1131,1093,1052$ & 1073, 1036, 951 & $\begin{array}{l}\text { 1201, 1129, 1073, } \\
1040,968\end{array}$ \\
\hline$[\alpha]_{24}^{\mathrm{D}}$ (methanol) & $-20.0^{\circ}$ (c 2.0) & $-33.0^{\circ}$ (c 1.0) & $-58.0^{\circ}$ (c 1.1) & $-38.0^{\circ}$ (c 1.0) \\
\hline \multirow[t]{2}{*}{ HPLC retention time $(\min )^{c}$} & 15.2 & 15.6 & 17.4 & 13.5 \\
\hline & 5 & 6 & 7 & 8 \\
\hline Appearance & White powder & White powder & White powder & White powder \\
\hline Molecular weight & 628 & 616 & 586 & 616 \\
\hline Molecular formula & $\mathrm{C}_{35} \mathrm{H}_{64} \mathrm{O}_{9}$ & $\mathrm{C}_{33} \mathrm{H}_{60} \mathrm{O}_{10}$ & $\mathrm{C}_{32} \mathrm{H}_{58} \mathrm{O}_{9}$ & $\mathrm{C}_{33} \mathrm{H}_{60} \mathrm{O}_{10}$ \\
\hline \multicolumn{5}{|l|}{ HR-MS $(m / z)$} \\
\hline Calculated: & 651.4448 & 639.4084 & 609.3978 & 661.3903 \\
\hline Found: & $651.4479(\mathrm{M}+\mathrm{Na})^{+} \mathrm{a}$ & $639.4105(\mathrm{M}+\mathrm{Na})^{+} \mathrm{b}$ & $609.4000(\mathrm{M}+\mathrm{Na})^{+} \mathrm{b}$ & $661.3920(\mathrm{M}+2 \mathrm{Na}-\mathrm{H})^{+} \mathrm{b}$ \\
\hline UV $\lambda_{\max }$ (methanol) $\mathrm{nm}(\varepsilon)$ & $237(20,000)$ & $237(12,000)$ & $236(12,500)$ & $236(16,300)$ \\
\hline \multirow[t]{4}{*}{$\mathrm{IR} v_{\max }(\mathrm{KBr}) \mathrm{cm}^{-1}$} & $3378,2956,2920,2851$ & $3372,2924,2854,1738$ & 3394, 2955, 2928, 2855, & 3336, 2954, 2922, \\
\hline & $1739,1665,1466,1457$ & $1661,1457,1377,1314$ & $1743,1161,1456,1377$ & $2872,2853,1737$ \\
\hline & $1377,1249,1215,1131$ & $1245,1215,1127,1073$ & $1216,1130,1074$ & $1664,1458,1377$ \\
\hline & $1074,1040,967$ & 1038,967 & 1037, 952 & $\begin{array}{l}\text { 1247, 1213, } 1127 \\
1069,1042,947\end{array}$ \\
\hline$[\alpha]_{24}^{\mathrm{D}}$ (methanol) & $-28.0^{\circ}$ ( с 0.1$)$ & $-50.0^{\circ}$ (с 0.1$)$ & $-50.0^{\circ}($ c 0.1$)$ & $-32.0^{\circ}(c 0.1)$ \\
\hline HPLC retention time $(\min )^{c}$ & 18.2 & 11.9 & 10.6 & 11.2 \\
\hline
\end{tabular}
$12.56 \mathrm{~min}$, which was identical to that of the authentic arabinono-1,4lactone derivative.

It was thought that it would be possible to determine the length of the alkyl chain and the substituted position of the hydroxyl group by analyzing the EI-MS fragmentation of the keto analog obtained through the decarboxylation at C-1 of the fatty-acid chain because the $\beta$-keto acid was unstable under acidic or alkaline conditions when

Table 1 Physicochemical properties of haplofungins

aLC/ESI-TOF MS, liquid chromatography coupled with time of flight mass spectrometry using electrospray ionization.

bHRFAB MS, high-resolution fast atom bombardment mass spectrscopy

${ }^{c}$ Condition of HPLC analysis is described in experimental section. 


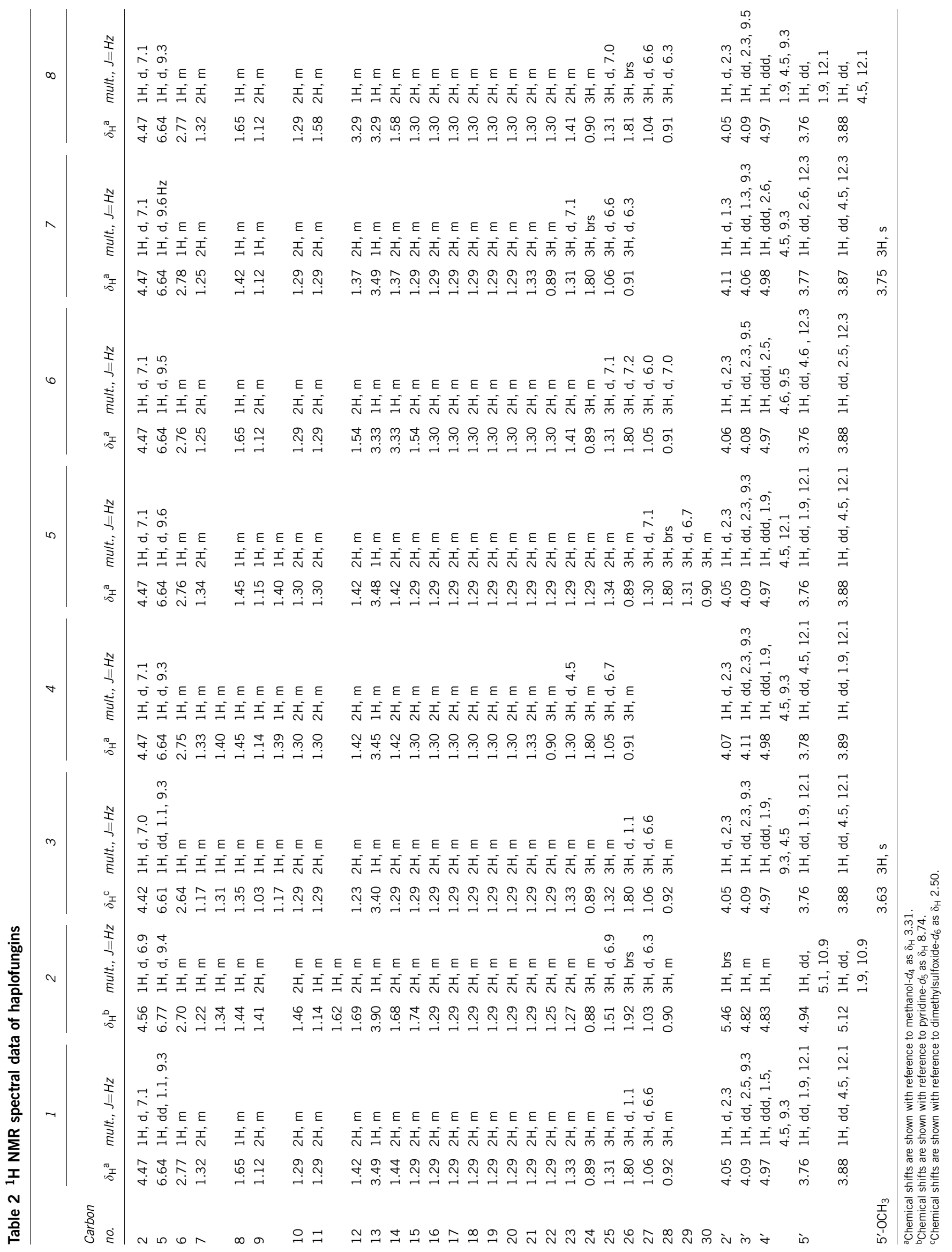


Table $3{ }^{13} \mathrm{C}$ NMR spectral data of haplofungins

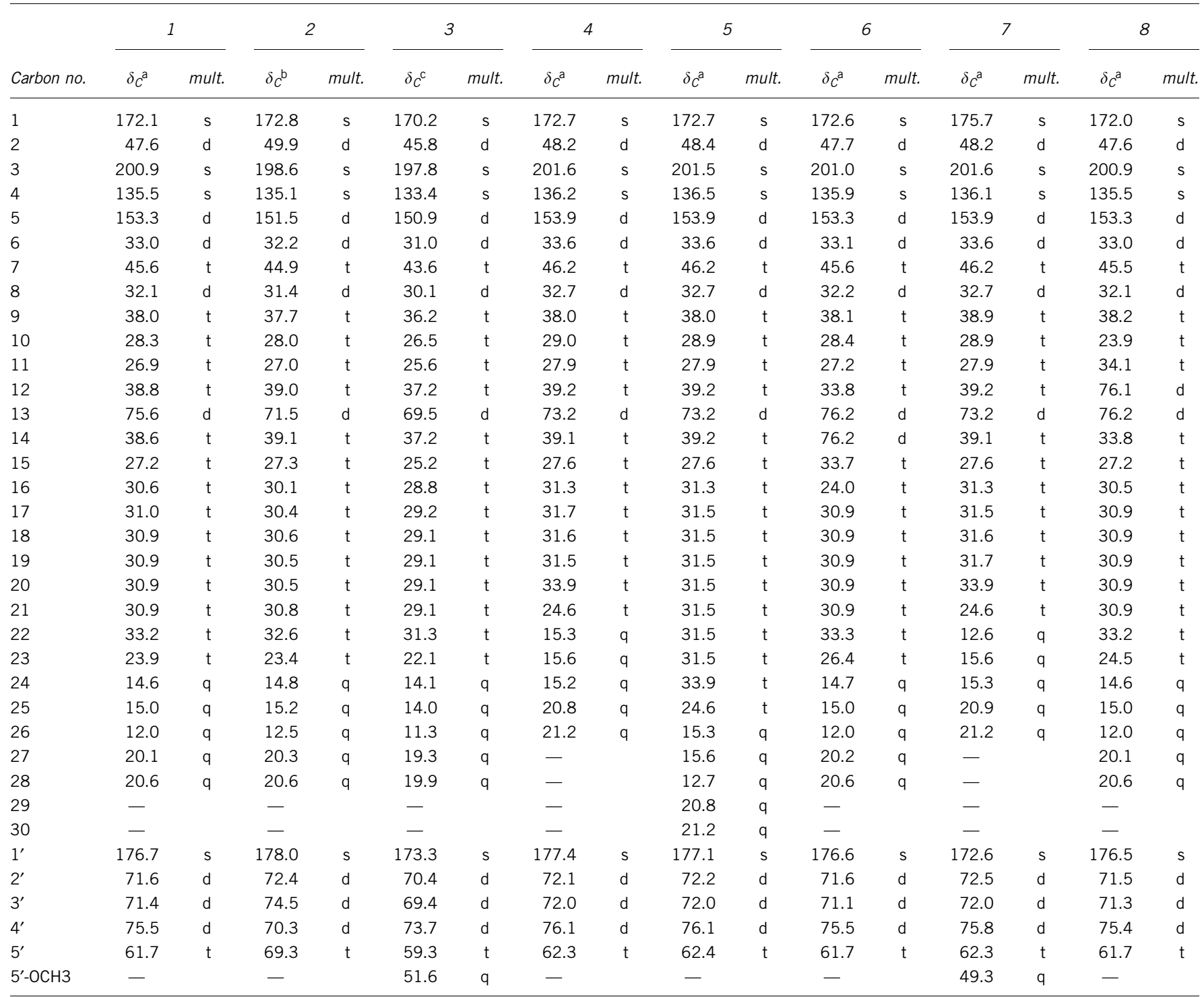

${ }^{a}$ Chemical shifts are shown with reference to methanol- $d_{4}$ as $\delta_{C} 49.0$.

${ }^{b}$ Chemical shifts are shown with reference to pyridine- $d_{6}$ as $\delta_{\mathrm{C}} 150.4$.

${ }^{c}$ Chemical shifts are shown with reference to dimethylsulfoxide- $d_{6}$ as $\delta_{\mathrm{C}} 39.5$

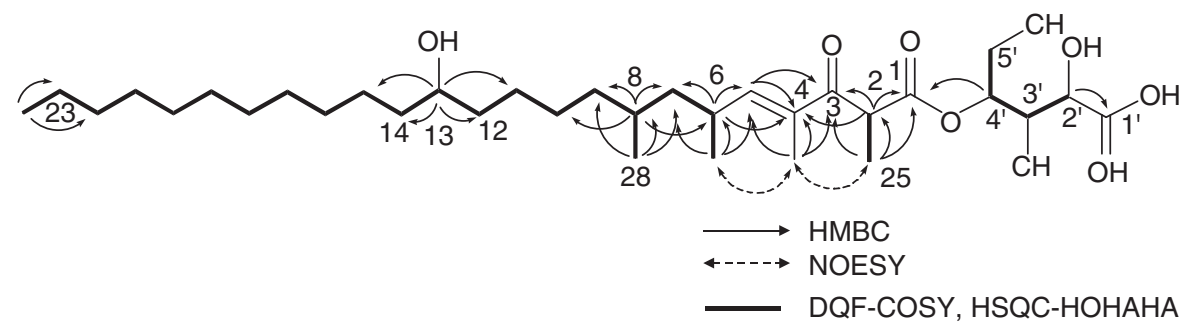

Figure 2 Selected ${ }^{1} \mathrm{H}-{ }^{1} \mathrm{H}$ COSY, HMBC and NOE correlations in haplofungin A (1).

making hydorolysate of haplofungins. For this purpose, 1 was treated with $5 \% \mathrm{HCl} / \mathrm{MeOH}$ at $105^{\circ} \mathrm{C}$ for $10 \mathrm{~h}$. The resultant was concentrated in vacuo followed by treatment with BSTFA in pyridine for $5 \mathrm{~min}$. Their EI-MS fragment patterns and retention times in the GC/MS analysis are shown in Figure 3 and Table 4. The substituted position of the hydroxyl group was determined by the alkyl chain length from the $\alpha$-cleavage sites at each side of the hydroxyl group. Fragmentation of the alkyl chain derivative (1a) from 1 on EI-MS gave fragments at $\mathrm{m} / \mathrm{z} 257$ and 325 , indicating that the oxidation site is C-13 (Figure 3). From these results, the planar structure of $\mathbf{1}$ was established as shown in Figure 1. 

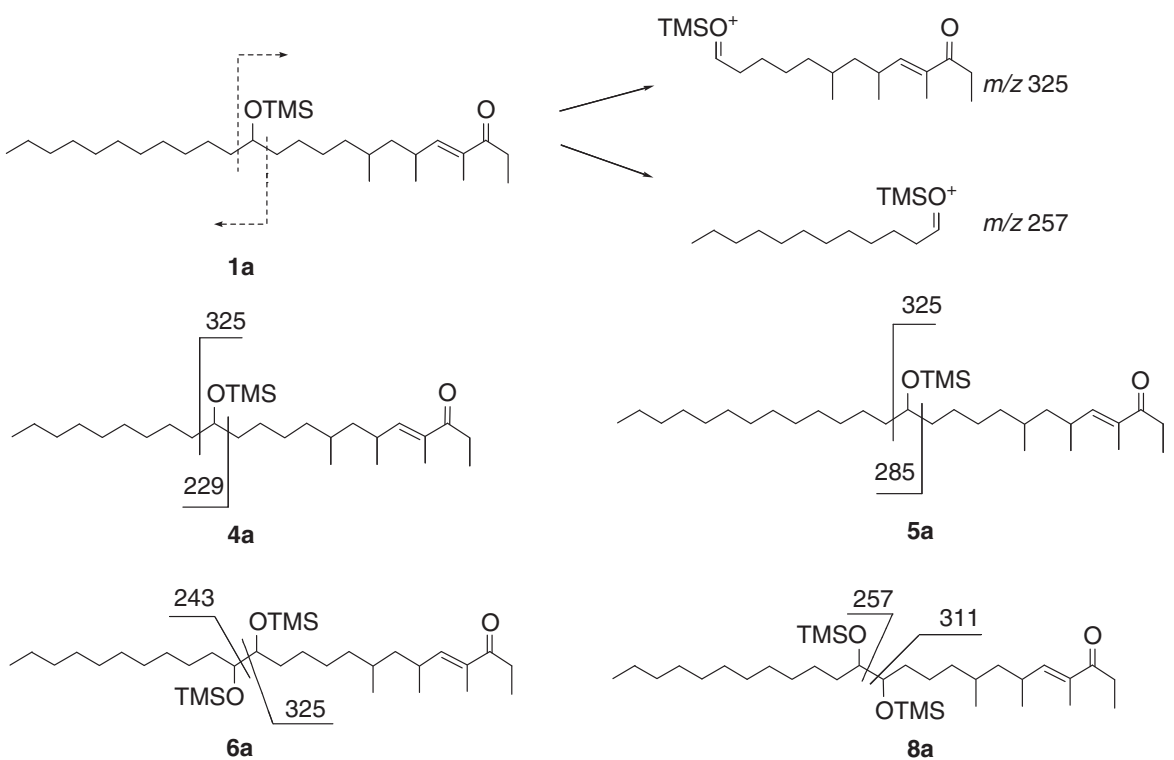

$8 \mathbf{a}$

Figure 3 El-MS fragmentation patterns of derived alkyl chain moieties. The ketone and long-chain moieties were produced by $\alpha$-cleavage reactions that occur on either side of the hydroxyl group with loss of enol ether moiety. For example, fragmentation of $1 \mathrm{a}$ on El-MS gave fragments at $\mathrm{m} / \mathrm{z} 357$ and 325 , indicating that the oxidation site is C-13.

Table 4 GC-MS retention times and EI-MS fragmentation patterns of TMS derivatives

\begin{tabular}{|c|c|c|c|c|c|}
\hline \multirow{3}{*}{$\begin{array}{l}\text { Compound } \\
1\end{array}$} & \multicolumn{2}{|c|}{$t_{R}(\min )$} & \multirow[b]{2}{*}{ Derivative } & \multirow{2}{*}{\multicolumn{2}{|c|}{ El-MS fragment ions $(\mathrm{m} / \mathrm{z})$}} \\
\hline & $\begin{array}{c}\text { Arabinono } \\
\text { lactone }\end{array}$ & $\begin{array}{l}\text { Alkyl } \\
\text { chain }\end{array}$ & & & \\
\hline & 12.56 & 33.91 & $1 \mathrm{a}$ & 257 & 325 \\
\hline 3 & 12.62 & 33.96 & $1 \mathrm{a}$ & 257 & 325 \\
\hline 4 & 12.58 & 31.23 & $4 a$ & 229 & 325 \\
\hline 5 & 12.63 & 36.52 & $5 a$ & 285 & 325 \\
\hline 6 & 12.55 & 35.52 & $6 a$ & 243 & 325 \\
\hline 7 & 12.62 & 31.26 & $4 a$ & 229 & 325 \\
\hline 8 & 12.54 & 35.39 & $8 a$ & 257 & 311 \\
\hline
\end{tabular}

\section{Structure elucidation of the minor components}

As described in the preceding paper, ${ }^{1}$ compounds $\mathbf{2 - 8}$ were isolated as minor components from a culture broth of SANK 26899. The analysis of each compound by LC/MS afforded molecular weights ranging from $572 \mathrm{Da}$ to $628 \mathrm{Da}$. Their mass differences were easily explained as the number of $\mathrm{CH}_{2}$ units or hydroxyl substituents from 1. To determine the location of hydroxyl groups, number of aliphatic carbons, and to identify an aldonic acid moiety, GC/MS analysis of TMS derivatives prepared from the methanolysis products of all minor compounds were used.

In addition to the results shown in Figure 3 and Table 4, the structures of the minor components were finally determined by $1 \mathrm{D}$ and 2D NMR spectra, as follows:

Structure of haplofungin B (2). The molecular formula of 2 was determined as $\mathrm{C}_{33} \mathrm{H}_{60} \mathrm{O}_{9}$ by HRTOF-MS, which was the same as that of $\mathbf{1}$. The ${ }^{1} \mathrm{H}$ and ${ }^{13} \mathrm{C}$ NMR spectra of $\mathbf{2}$ were very similar to those of $\mathbf{1}$, except for the signals for the aldonic acid moiety. In the HMBC experiment, ${ }^{1} \mathrm{H}-{ }^{13} \mathrm{C}$ long-range correlations were observed from $\mathrm{H}$ $5^{\prime} \mathrm{a}-$ and $5^{\prime} \mathrm{b}$-oxygenated methylene protons at $\delta 4.94$ and 5.12 to the
C-1 ester carbonyl carbon at $\delta 172.8$, which established that the C-5 in aldonate moiety is attached to the $\mathrm{C}-1$ in the fatty-acid moiety (Figure 1). During purification, it was observed that 1 was easily converted to 2 under alkaline conditions (data not shown). The structure of 2 was thus determined to be an acyl rearrangement product of 1 .

Structure of haplofungin $C$ (3). The molecular formula of 3,determined as $\mathrm{C}_{34} \mathrm{H}_{62} \mathrm{O}_{9}$ by HRTOF-MS, differed from that of 1 by one $\mathrm{CH}_{2}$ unit. The ${ }^{1} \mathrm{H}$ and ${ }^{13} \mathrm{C}$ NMR spectra in DMSO- $d_{6}$ indicated the presence of methyl ester $\left(\delta_{\mathrm{H}} 3.63, \delta_{\mathrm{C}} 51.6\right)$. The structures of the aldonate moiety and the fatty-acid moiety were identified by GC/MS analysis (Table 4). The fragment patterns of the hydrolyzed TMS derivatives of the methanolysis products were identical with those of $\mathbf{1}$. In the $\mathrm{HMBC}$ spectrum, correlation from $1^{\prime}-\mathrm{OCH}_{3}$ methoxyl protons at $\delta 3.63$ to $\mathrm{C}-1^{\prime}$ carbonyl carbon at $\delta 173.3$ in the aldonic acid moiety was observed. A ${ }^{1} \mathrm{H}-{ }^{13} \mathrm{C}$ long-range correlation was also observed from $\mathrm{H}-4^{\prime}$-oxygenated methine proton at $\delta 4.97$ to C-1 ester carbonyl carbon at $\delta 170.2$, which established that the C-4' in aldonate moiety is attached to the $\mathrm{C}-1$ in the fatty acid moiety. From these results, the structure of $\mathbf{3}$ was elucidated to be the methyl ester of $\mathbf{1}$ (Figure 1).

Structure of haplofungin $D(4)$. The molecular formula of $\mathbf{4}$ was determined as $\mathrm{C}_{31} \mathrm{H}_{56} \mathrm{O}_{9}$ by high-resolution fast atom bombardment mass spectrscopy (HR-FABMS), which was different from that of 1 by two $\mathrm{CH}_{2}$ units. The structures of the aldonate moiety and the fattyacid moiety were also determined by GC/MS analysis and the fragment ion $(m / z 229)$ originated from the TMS derivative (4a) of the fatty acid indicated that the length of the alkyl chain was shorter than 1 by two $\mathrm{CH}_{2}$ units (Figure 3, Table 4). The ${ }^{13} \mathrm{C}$ NMR spectrum readily showed the absence of two methylene units in the alkyl chain. In the $\mathrm{HMBC}$ spectrum, ${ }^{1} \mathrm{H}-{ }^{13} \mathrm{C}$ long-range correlation was observed from oxygenated $\mathrm{H}-4^{\prime}$ methine proton at 4.98 to $\mathrm{C}-1$ ester carbonyl carbon at 172.7 , which established that the $\mathrm{C}-4^{\prime}$ in aldonic acid moiety is attached to the $\mathrm{C}-1$ in the fatty-acid moiety. Combining the results of the NMR and GC/MS experiments, the structure of 4 was determined to be as shown in Figure 1. 
Structure of haplofungin E (5). The molecular formula of 5 was determined as $\mathrm{C}_{35} \mathrm{H}_{64} \mathrm{O}_{9}$ by HRTOF-MS and it was shown that 5 was two $\mathrm{CH}_{2}$ units larger than 1 . The identification of the aldonate moiety and the structure analysis of the fatty-acid moiety were carried out by GC/MS analysis. The fragment ion $(m / z 285)$ from the TMS derivative (5a) of the fatty acid indicated that the alkyl chain length was longer than that of 1 by two $\mathrm{CH}_{2}$ units (Figure 3, Table 4). Two newly appeared methylene carbons, in the alkyl chain, were observed in the ${ }^{13} \mathrm{C}$ NMR spectrum. In the $\mathrm{HMBC}$ spectrum, ${ }^{13} \mathrm{C}-{ }^{1} \mathrm{H}$ long-range correlation from the oxygenated methine proton at $\delta 4.97\left(\mathrm{H}-4^{\prime}\right)$ to the ester carbonyl carbon at $\delta 172.7(\mathrm{C}-1)$ indicated that the $\mathrm{C}-4^{\prime}$ in the aldonate moiety is attached to ester carbonyl carbon (C-1) in the fatty-acid moiety. From these results, the structure of $\mathbf{5}$ was determined to be as shown in Figure 1.

Structure of haplofungin $F(6)$. The molecular formula of $\mathbf{6}$ was determined to be $\mathrm{C}_{33} \mathrm{H}_{60} \mathrm{O}_{10}$ by HR-FABMS and shown to have one additional oxygen in the molecule compared to 1 . The ${ }^{13} \mathrm{C} N M R$ spectrum readily showed the presence of one newly observed oxygenated methine carbon signal at $\delta$ 76.2. These data strongly suggested that one hydroxyl group was introduced into the structure of 1 . To clarify the oxygenated sites, TMS derivatives of the aldonate moiety and fatty-acid moiety were subjected to GC/MS analysis and the appearance of the fragment ions $(\mathrm{m} / z 243$ and 325) caused by the oxidative cleavage of 1,2-diol in the TMS derivative of the fatty acid (6a) showed the substituted positions of two hydroxyl groups to be at C-13 and C-14 (Figure 3, Table 4). In the HMBC spectrum, ${ }^{1} \mathrm{H}-{ }^{13} \mathrm{C}$ long-range correlation was observed from $\mathrm{H}$-4'-oxygenated methine proton at $\delta 4.97$ to $\mathrm{C}-1$ ester carbonyl carbon at $\delta 172.6$, which established that the C- $4^{\prime}$ in aldonic acid moiety is attached to C-1 in the fatty-acid moiety. From these results, the structure of 6 was determined to be as shown in Figure 1.

Structure of haplofungin $G(7)$. The molecular formula of 7 was determined to be $\mathrm{C}_{32} \mathrm{H}_{58} \mathrm{O}_{9}$ by HR-FABMS. It differs from that of 4 by one $\mathrm{CH}_{2}$ unit. The ${ }^{1} \mathrm{H}$ and ${ }^{13} \mathrm{C}$ NMR spectra indicated the presence of a methoxyl group $\left(\delta_{\mathrm{H}} 3.75, \delta_{\mathrm{C}} 49.3\right)$. GC/MS analysis of the TMS derivative showed the same fragment pattern as that of 4 (Figure 3, Table 4). In the $\mathrm{HMBC}$ spectrum, correlation between $1^{\prime}-\mathrm{OCH}_{3}$ protons at $\delta 3.75$ to $\mathrm{C}-1^{\prime}$ carbonyl carbon at $\delta 172.6$ in the aldonic acid moiety was observed. ${ }^{1} \mathrm{H}-{ }^{13} \mathrm{C}$ long-range correlation was also observed from the $\mathrm{H}-4^{\prime}$ oxygenated methine proton at $\delta 4.98$ to the C-1 ester carbonyl carbon at $\delta 175.7$, which established that the C- $4^{\prime}$ in the aldonic acid moiety is attached to $\mathrm{C}-1$ in the fatty-acid moiety (Figure 1). From these results, the structure of 7 was established to be the methyl ester of 4 .

Structure of haplofungin $H$ (8). The molecular formula of $\mathbf{8}$ was determined to be $\mathrm{C}_{33} \mathrm{H}_{60} \mathrm{O}_{10}$ by HR-FABMS, which was the same as $\mathbf{6}$. Typical two fragment ions (m/z 311 and 257) derived from the TMS derivative of the fatty acid ( $8 \mathbf{8}$ ) by the 1,2-diol cleavage between C-12 and $\mathrm{C}-13$ were observed. The ${ }^{13} \mathrm{C}$ NMR spectrum readily showed the presence of one newly observed oxygenated methine carbon signal at 76.1 in the alkyl chain. As the same hydroxylation sites as $\mathbf{6}$ were expected in this case, GC/MS analysis was carried out. Consequently, the substituted positions of the two hydroxyl groups were determined to be at $\mathrm{C}-12$ and 13 (Figure 3 , Table 4). ${ }^{1} \mathrm{H}-{ }^{13} \mathrm{C}$ long-range correlation was observed from the oxygenated $\mathrm{H}-4^{\prime}$ methine proton at $\delta 4.97$ to the C-1 ester carbonyl carbon at $\delta 172.0$, which established that the $\mathrm{C}-4^{\prime}$ in the aldonic acid moiety is attached to the C-1 in the fatty-acid moiety. Thus, the structure of $\mathbf{8}$ was determined to be the C-12-hydroxylated homolog of $\mathbf{1}$ as shown in Figure 1.

\section{DISCUSSION}

Eight new compounds were isolated as fungal IPC synthase inhibitors. Their planer structures have been elucidated by $1 \mathrm{D}$ and 2D NMR experiments and GC/MS analysis of the TMS derivatives from degradation products prepared by methanolysis. From these results, it was shown that these homologs were composed of an arabinonic acid moiety and a $\beta$-keto acid with a long unsaturated hydroxyalkyl chain as partial structures. Interestingly, these units have a high similarity to the partial structures of two known IPC synthase inhibitors, khafrefungin ${ }^{3}$ and rustmicin. ${ }^{4,5}$ The arabinonic acid and the hydroxylated long-chain fatty-acid units are common to khafrefungin and the $\alpha$-methyl- $\beta$-keto acid unit is common to rustmicin. These units are reported to be indispensable for the biological activities of these compounds. ${ }^{6-8}$ A 14-membered macrolide, the same as rustmicin, has been obtained by macrolactonization between C-1 and C-13 of $\beta$-keto acid prepared from 1 by hydrolysis under mild alkaline condition. However, this macrolide showed no biological activity (data not shown). It was evident that haplofungin has a very unique structure which possesses partial structures of these two known compounds. The core structure of haplofungins also seems to mimic the structure of phytoceramide, which is the substrate of IPC synthase. However, their antifungal activities were weak, ${ }^{1}$ in contrast to the strong inhibitory activities against IPC synthase. If the structural features and the antifungal activities of haplofungins are improved, these derivatives will be candidates for new chemotherapeutic drugs for fungal diseases. The absolute structure of haplofungin A will be reported in the succeeding paper. ${ }^{9}$

\section{EXPERIMENTAL SECTION}

\section{General experimental procedures}

The 1D and 2D NMR spectra of haplofungins were recorded on a Bruker AVANCE 500 spectrometer (Bruker, Rheinstetten, Germany) equipped with a cryogenic probe. The data set acquired for each sample consisted of $1 \mathrm{D}^{1} \mathrm{H},{ }^{13} \mathrm{C}$ NMR, gs-DQF-COSY, NOESY, gs-HSQC, gs-HMBC and gs-HSQC-HOHAHA experiments which were adopted from Bruker standard pulse microprograms. The HR-FABMS spectra were recorded on a Micromass Autospec mass spectrometer (Micromass, Manchester, UK). The HRTOF-MS spectra were obtained on a Micromass LCT equipped with an electrospray ion (ESI) source. Optical rotations were measured with a JASCO DIP-370 spectropolarimeter (JASCO, Tokyo, Japan). IR spectra were obtained on a JASCO FT/IR-8900 spectrometer. The UV spectra were recorded on a Shimadzu UV-265FW spectrometer (Shimadzu, Kyoto, Japan). GC/MS analyses were carried out using an Agilent GC/MSD spectrometer (Agilent, Santa Clara, CA, USA; EI-MS detector, 5973; GC system, 6890; carrier gas, He). The LC/MS analyses were carried out using an Agilent LC/MSD equipped with an ESI ion source. The analytical HPLC operations were performed on an Agilent HP1100 HPLC system. The HPLC analyses were measured on an Agilent 1100 system (column, Cadenza CD-C18 (4.6×75 mm, Imtakt Co., Japan); mobile phase, A: $0.1 \%$ trifluoroacetic acid, B: acetonitrile, 65-95\% B (0-15 min), 95\% B (15-20 min), linear gradient, flow rate, $0.6 \mathrm{ml} \mathrm{min}^{-1}$; detection UV $240 \mathrm{~nm}$ ).

\section{GC/MS analysis of components prepared from haplofungins by methanolysis}

The compound 1 was treated with methanol containing $5 \% \mathrm{HCl}$ at $80^{\circ} \mathrm{C}$ for $4 \mathrm{~h}$ in a sealed ampoule, and the reaction mixture was dried over a stream of $\mathrm{N}_{2}$ gas. The residue was then dissolved in pyridine and BSTFA was added. The mixture was allowed to stand at room temperature for $5 \mathrm{~min}$. The product was subsequently subjected to GC/MS analysis under the following conditions: HP$5 \mathrm{MS}$ capillary column (Agilent, $0.25 \times 30 \mathrm{~mm}$ ). The column temperature was programmed to rise $5^{\circ} \mathrm{C} \mathrm{min}^{-1}$ from $120^{\circ} \mathrm{C}$ to $240^{\circ} \mathrm{C}$. The flow rate of the He carrier gas was $1.5 \mathrm{ml} \mathrm{min}^{-1}$. The retention times of the TMS-derivatives are shown in Table 4. Authentic D-arabinono-1,4-lactone was prepared from D-arabinose by oxidation according to the method of Han et al. ${ }^{10}$ 
1 Ohnuki, T. et al. Haplofungins, novel inositol phosphorylceramide synthase inhibitors, from Lauriomyces bellulus SANK 26899 I. Taxonomy, fermentation, isolation, and biological activities. J. Antibiot. (e-pub ahead of print 31 July 2009; doi:10.1038/ ja.2009.72).

2 Vértesy, L. et al. Novel hormone-sensitive lipase inhibitors from Streptomyces $s p$ DSM13381. II. Isolation, structure elucidation and biological properties. J. Antibiot. 55, 480-489 (2002)

3 Mandala, S. M. et al. Khafrefungin, a novel inhibitor of sphingolipid synthesis. J. Biol.Chem. 272, 32709-327014 (1997).

4 Takatsu, T. et al. Rustmicin, a new macrolide antibiotic active against wheat stem rust fungus. J. Antibiot. 38, 1806-1809 (1985).

5 Mandala, S. M. et al. A potent antifungal agent, inhibits sphingolipid synthesis at inositol phosphoceramide synthase. J. Biol. Chem. 273, 14942-14949 (1998).
6 Wakabayashi, T., Mori, K. \& Kobayashi, S. Total synthesis and structure elucidation of khafrefungin. J. Am. Chem. Soc. 123, 1372-1375 (2001)

7 Kobayashi, S., Mori, K., Wakabayashi, T., Yasuda, S. \& Hanada, K. Convergent total synthesis of khafrefungin and its inhibitory activity of fungal sphingolipid syntheses. J. Org. Chem. 66, 5580-5584 (2001).

8 Sakoh, H. et al. Novel galbonolide derivatives as IPC synthase inhibitors: design, synthesis and in vitro antifungal activities. Bioorg. Med. Chem. Lett. 14, 143-145 (2004).

9 Ohnuki, T., Yano, T., Furukawa, Y. \& Takatsu, T. Haplofungins, novel inositol phosphorylceramide synthase inhibitors, from Lauriomyces bellulus SANK 26899 III. Absolute structure of haplofungin A. J. Antibiot. (In press).

10 Han, S. Y., Joullié, M. M., Fokin, V. V. \& Petasis, N. A. Spectroscopic, crystallographic and computational studies of the formation and isomerization of cyclic acetals and ketals of pentonolactones. Tetrahedron Asymmetry 5, 2535-2562 (1994). 